\title{
How have researchers defined and used the concept of 'continuity of care' for chronic conditions in the context of resource-constrained settings? A scoping review of existing literature and a proposed conceptual framework
}

\author{
Lana Meiqari ${ }^{1,2^{*}}$ (D), Tammam Al-Oudat ${ }^{3}$, Dirk Essink ${ }^{1}$, Fedde Scheele ${ }^{1}$ and Pamela Wright ${ }^{4}$
}

\begin{abstract}
Background: Within the context of the growing burden of non-communicable diseases (NCDs) globally, there is limited evidence on how researchers have explored the response to chronic health needs in the context of health policy and systems in low- and middle-income countries. Continuity of care $(\mathrm{CoC})$ is one concept that represents several elements of a long-term model of care. This scoping review aims to map and describe the state of knowledge regarding how researchers in resource-constrained settings have defined and used the concept of CoC for chronic conditions in primary healthcare.
\end{abstract}

Methods: This scoping review adopted the modified framework for interpretive scoping literature reviews. A systematic literature search in PubMed was performed, followed by a study selection process and data extraction, analysis and synthesis. Extracted data regarding the context of using $\mathrm{CoC}$ and the definition of $\mathrm{CoC}$ were analysed inductively to identify similar patterns; based on this, articles were divided into groups. MaxQDA was then used to re-code each article with themes according to the $\mathrm{CoC}$ definition to perform a cross-case synthesis under each identified group.

Results: A total of 55 peer-reviewed articles, comprising reviews or commentaries and qualitative or quantitative studies, were included. The number of articles has increased over the years. Five groups were identified as those (1) reflecting a change across stages or systems of care, (2) mentioning continuity or lack of continuity without a detailed definition, (3) researching CoC in HIV/AIDS programmes and its scaling up to support management of NCDs, (4) researching CoC in NCD management, and (5) measuring CoC with validated questionnaires.

Conclusion: Research or policy documents need to provide an explicit definition of $\mathrm{CoC}$ when this terminology is used. A framework for $\mathrm{CoC}$ is suggested, acknowledging three components for $\mathrm{CoC}$ (i.e. longitudinal care, the nature of the patient-provider relationship and coordinated care) while considering relevant contextual factors, particularly access and quality.

Keywords: Continuity of care, long-term care, chronic care, resource-constrained setting, primary healthcare, health policy and systems

\footnotetext{
* Correspondence: lana.meiqari@vu.nl

${ }^{1}$ Athena Institute for Research on Innovation and Communication in Health

and Life Sciences, Faculty of Sciences, Vrije Universiteit Amsterdam, De

Boelelaan 1085, 1081 HV Amsterdam, The Netherlands

${ }^{2}$ Department of Public Health, Institute of Tropical Medicine, Antwerp,

Belgium

Full list of author information is available at the end of the article
}

(c) The Author(s). 2019 Open Access This article is distributed under the terms of the Creative Commons Attribution 4.0 International License (http://creativecommons.org/licenses/by/4.0/), which permits unrestricted use, distribution, and

reproduction in any medium, provided you give appropriate credit to the original author(s) and the source, provide a link to the Creative Commons license, and indicate if changes were made. The Creative Commons Public Domain Dedication waiver (http://creativecommons.org/publicdomain/zero/1.0/) applies to the data made available in this article, unless otherwise stated. 


\section{Introduction}

Improved health systems have been essential in efforts to achieve the Millennium Development Goals of reducing child and maternal mortality and combating HIV/AIDS and other communicable diseases; these health improvements have resulted in higher life expectancy and ageing populations worldwide [1]. Nevertheless, in many lowand middle-income countries (LMICs) the burden of communicable, maternal, neonatal and nutritional disorders has remained a priority, while a growing burden of non-communicable diseases (NCDs) and injuries has concurrently emerged as a new challenge [2]. In the era of Sustainable Development Goals, strategies and policies proposed to strengthen health systems to cope with this double burden include achieving universal health coverage, prioritising primary and community care services, and strengthening referral systems, along with efforts towards patient empowerment. However, implementing such policies in LMICs demands a radical paradigm shift in how health services are managed, delivered and funded [3]. For example, health services previously organised to provide care for acute and episodic conditions now need to provide long-term care across disciplines to manage chronic diseases effectively, efficiently and cost-effectively $[4,5]$.

The most common conceptualisation of designing and providing care for chronic conditions is the Chronic Care Model (CCM) developed by Wagner in the 1990s [6]; the CCM emphasised the productive interaction of the "informed and activated" patient with the "prepared and proactive" healthcare team, which will lead to improved health outcomes. The CCM argued that a productive patient-provider interaction needs a comprehensive system change in the organisation of primary healthcare in terms of resources and policies, self-management support, decision support, delivery system design and clinical information systems [6]. This model was adopted and expanded to the global level through WHO's Innovative Care for Chronic Conditions (ICCC) framework, which suggested building blocks at three levels of the health system (i.e. community, healthcare organisation and positive policy environment), "that can be used to create or re-design a healthcare system to more effectively manage long-term health problems" [7]. At the healthcare organisation level, the building blocks were to promote continuity and coordination, encourage quality through leadership and incentives, organise and equip healthcare teams, use information systems, and support self-management and prevention [7]. Over the years, several entangled concepts and frameworks have been used to define essential elements of a long-term model of care for research and policy at both global and national levels, including continuity or coordination or integration of care, patient- or people-centred care, case management, continuum of care, and holistic care $[3,6,7]$. A literature review identified three core values and themes shared by these concepts, namely (1) personal relationship between patient and provider, (2) communication of relevant information between providers, and (3) cooperation between providers within and between healthcare settings [8].

However, all of these concepts and frameworks, including $\mathrm{CCM}$, were defined and designed based on research in high-income countries. There is scarce evidence on how the response to chronic health needs has been translated into the context of LMICs, which face additional challenges such as weak health systems and constrained resources. Furthermore, researchers and policy-makers are increasingly recognising that there is no 'one-size-fits-all' or 'one model' for health interventions [3]; therefore, differences in contexts, populations, and even times must be considered when applying health concepts and interventions in research and policy $[9,10]$. There have been several attempts to adapt models of chronic care to the context of LMICs. For example, a recent article synthesised evidence from primary qualitative research and found that all themes of CCM were included in the analysed studies, in addition to four further themes, namely quality of communication between health professionals and patients, availability of essential medicines, diagnostics and trained personnel at decentralised levels of healthcare, and mechanisms for coordination between healthcare providers [11]. Another article used South Africa as a case study to analyse the application of the ICCC Framework in light of multimorbidity due to comorbid NCDs and infectious chronic diseases, and highlighted the importance of patient perspectives, experiences and capacity that contribute to better treatment adherence, healthcare utilisation and health outcomes.

One concept which is driven by the patient perspective and their sense of their relationship with the healthcare provider and the health system is 'continuity of care' (CoC) [12]. Different definitions and perspectives for $\mathrm{CoC}$ have been identified by research conducted in high-income countries (Additional file 1). Globally, the ICCC Framework introduced the element of continuity as care "planned and thoughtful over the course of the condition" [7], which emphasised the role of organisations in providing proactive care, including scheduled follow-up visits. Later, WHO adopted a definition of $\mathrm{CoC}$ as "the degree to which a series of discrete health care events is experienced by people as coherent and interconnected over time, and consistent with their health needs and preferences" [3]. This definition focuses on $\mathrm{CoC}$ as a process experienced by patients accessing care that fulfils their health needs and leads to better outcomes, such as higher patient satisfaction and quality of 
life, improved delivery of preventive services, fewer visits to emergency departments, and lower hospitalisation rates [13-16]. From the perspective of complex systems, $\mathrm{CoC}$ became a benchmark for quality of care [17], and subsequent research often focused on $\mathrm{CoC}$ as an outcome for ongoing complex interactions within the health system, aimed at finding evidence on how better to achieve $\mathrm{CoC}$ [10]. In general, $\mathrm{CoC}$ definitions share three common themes or elements, namely (1) care delivered over time with as few doctors as possible (i.e. longitudinal care), (2) a caring relationship between patients and health professionals (i.e. patient-professional relationship), and (3) cooperation and communication of relevant information between providers within and between care settings (i.e. coordinated care).

To further synthesise available evidence on chronic care in resource-constrained settings as experienced by patients and providers, we decided to focus on the concept of CoC. We aim to map and describe the state of knowledge regarding how researchers in resource-constrained settings defined and used definitions of the concept of $\mathrm{CoC}$ for chronic conditions in primary healthcare. This article uses a scoping review methodology as it aims to clarify a complex concept with an exploratory review of the literature $[18,19]$.

\section{Methods}

This scoping review adopted Daudt et al.'s modifications [20] to Arksey and O'Malley's framework for interpretive scoping literature reviews [21], using the five steps of identifying the research question, identifying relevant studies, study selection, charting the data, and collating, summarising and reporting the results.

\section{Identifying the research question}

Given the aim of this review, the following research questions were formulated:

1) What type of research used the concept of $\mathrm{CoC}$ in primary healthcare in resource-constrained settings?

2) What definitions and/or frameworks for $\mathrm{CoC}$ were used?

3) What measurements for $\mathrm{CoC}$ were used?

\section{Identifying relevant studies}

A literature search was performed in PubMed using relevant keywords and index terms. Search terms were developed following the elements of population, concept and context. The population under study is composed of patients who have chronic conditions and need longterm care, including those with chronic NCDs or communicable diseases. The concept is $\mathrm{CoC}$ at the primary healthcare level. The context is resource-constrained settings (i.e. LMICs). Detailed tables on the search terms used are presented in Additional file 2. The search covered existing publications, reporting quantitative and qualitative results, in English, with no time restrictions.

\section{Study selection}

One researcher (LM) screened titles and abstracts using the Rayyan QCRI application to choose relevant records [22]; full texts were obtained and read to assess each study for inclusion, based on the criteria that papers described the need or use of $\mathrm{CoC}$ in primary healthcare in resource-constrained settings, without limitations to the type of study design, accepting primary research studies, systematic reviews, meta-analyses and editorials.

This review focuses on the use of definitions and/or frameworks for data collection or in writing the article; it does not attempt to summarise evidence for any outcome or measurement. Thus, no quality assessment was performed during the process of selection.

\section{Charting the data}

Data extraction, analysis and synthesis involved an iterative process of reading and re-reading the selected studies. Essential information was extracted into a standardised spreadsheet, including author, publication year, research aim/objective, country, disease or population under investigation, research design, context for using $\mathrm{CoC}, \mathrm{CoC}$ definition, framework, measurement (when relevant), and results.

\section{Collating, summarising and reporting the results}

Firstly, a thematic analysis was used in which extracted data regarding the context of using $\mathrm{CoC}$ and $\mathrm{CoC}$ definition were analysed inductively to identify similar patterns. Based on the identified themes, articles were divided into groups. Secondly, MaxQDA was used to re-code each article with themes focused on $\mathrm{CoC}$ definition and its three items of longitudinal care, patient-professional relationships, and coordinated care. Consequently, we performed a cross-case synthesis for the articles within each group to compose the findings.

\section{Results \\ Study selection}

The database search produced 2116 records, of which 1982 were excluded by title/abstract screening. Full texts of the remaining 134 records were examined and those that did not use or define $\mathrm{CoC}$ were discarded. Finally, 55 peer-reviewed articles were selected for review.

\section{Study characteristics}

An overview of each article is available in Table 1. While all identified articles were published in the new millennium, the number of articles increased from 1 article in 
2002-2005 to 2-5 articles per year in the following years, jumping to 19 articles in 2015 (34.6\%).

The selected articles included $18(32.7 \%)$ reviews or commentaries; 13 (23.6\%) qualitative studies; 12 (21.8\%) articles describing interventions to manage chronic diseases; 10 (18.2\%) surveys; and 2 (3.6\%) cohort studies. Half of the reviews or commentaries were region or country specific. Half of the qualitative studies were disease specific.

A geographical location was specified for 46 articles, as Asia $(n=25 ; 54.4 \%)$, Africa $(n=14,30.4 \%)$ or South America $(n=7,15.2 \%)$. The largest proportion of the articles from Asia referred to China $(n=8)$, followed by Malaysia $(n=4)$ and India $(n=4)$. All of the articles from China were quantitative studies. Most of the articles from Africa referred to South Africa $(n=5)$ and Tanzania $(n=3)$. The articles from South America were observational; there were no intervention studies. The main three categories of investigated conditions were either not specified $(n=19,34.6 \%)$, diabetes mellitus or hypertension or both $(n=15,27.3 \%)$, or HIV $(n=12$, $21.8 \%)$, with half of these $(n=6)$ connecting HIV/AIDS care to other NCDs.

\section{List of used keywords across articles}

Different keywords and word combinations were used to reflect the concept of $\mathrm{CoC}$; four groups accommodated these keywords, as follows:

1) continued/continuous/continuity (i.e. continuity of patient care, continuity of healthcare, personal continuity of care, continuity of care record, care continuity, continued care, or continuous care);

2) continuum (i.e. continuum of care, continuum of care from prevention to treatment, continuum of disease care (e.g. continuum of HIV care), care continuum, chronic disease continuum or chronic disease care continuum);

3) continuity (i.e. coordination or integrated care); and

4) lack of continuity (i.e. discontinuity or fragmentation).

\section{Identified groups}

The articles were divided into five groups based on their use of the $\mathrm{CoC}$ concept, namely (1) reflecting a change across stages or systems of care $(n=13 ; 24 \%)$, (2) mentioning continuity or lack of continuity without a detailed definition ( $n=20 ; 36 \%$ ), (3) researching $\mathrm{CoC}$ in HIV/AIDS programmes and its scaling up to support NCD management ( $n=9 ; 16 \%)$, (4) researching CoC in NCD management ( $n=11 ; 20 \%)$, and (5) measuring $\mathrm{CoC}$ with validated questionnaires $(n=2 ; 4 \%)$. The results about how the $\mathrm{CoC}$ was described are presented below, and analysed under each group of articles.

\section{Group 1. Reflecting a change in disease stages or systems of care}

Six reviews defined care for chronic illnesses as the provision of services across the continuum of care. Chronic care services contained primary prevention, secondary prevention, diagnosis, treatment, management, complication detection, survivorship, rehabilitation care, and palliative and end-of-life care [23-28]. This approach reflects services needed with changes in disease stages; most of the early services are available at the primary healthcare level, while advanced services are provided at secondary levels.

Two different settings used continuity as a concept in the context of 'transition of care', namely chronic disease care and management for prisoners to ensure consistent transition of care from community to prison and back [29] and the transition of care for children with chronic diseases moving from paediatric to adolescent to adult clinical settings [30-32]. The children's transition process was described either as a $\mathrm{CoC}$ in two empirical studies from Brazil and Thailand [30, 31], or as a continuum of care in one review [32]. The qualitative research from Brazil evaluated $\mathrm{CoC}$ for children and adolescents from the perspectives of their families, healthcare providers and managers of local healthcare networks [31]. The authors defined $\mathrm{CoC}$ as "an aspect of care experienced over time by individuals who use health care services and is determined by the integration ability of these services to coordinate health care actions coherently" [31]. Central aspects discussed by participants included access to healthcare networks, communitybased versus hospital-based care, continuity of information, referral systems, development of one unified treatment plan to be followed up by specialists and family doctors, and availability of resources, including medications.

Three articles mentioned $\mathrm{CoC}$ for chronic diseases in emergency settings. In emergencies, $\mathrm{CoC}$ delivery faces additional challenges with a mobile or traumatised population and a broken health system [33, 34]. Access was an essential precondition for treatment, follow-up and retention [33-35]. Rabkin et al. [34] discussed challenges in providing adequate care for NCDs in emergencies and ensuring continuity, which was defined as "the need to deliver coordinated services over time". The types of interventions used by HIV/AIDS programmes that could support the provision of chronic care during emergencies were summarised. Examples included paper-based or electronic appointment systems, patientheld records, peer educators and patient support groups, and mobile phone apps and text reminders to facilitate retention. 
Table 1 Study characteristics of included peer-reviewed articles $(n=55)$, divided by the five groups identified based on their use of the 'continuity of care' concept

\begin{tabular}{|c|c|c|c|c|}
\hline $\begin{array}{l}\text { First author, } \\
\text { year }\end{array}$ & Study type & Condition & Location $^{a}$ & Main focus of the article \\
\hline \multicolumn{5}{|c|}{ Group 1: Reflecting a change in stages or systems of care } \\
\hline $\begin{array}{l}\text { Robles, } 2004 \\
{[28]}\end{array}$ & Review & Chronic diseases & Americas & $\begin{array}{l}\text { A public health framework for chronic disease } \\
\text { prevention and control }\end{array}$ \\
\hline $\begin{array}{l}\text { Mayige,2011 } \\
{[25]}\end{array}$ & Review & NCDs & Tanzania & NCD services \\
\hline $\begin{array}{l}\text { Pakdeeprom, } 2012 \\
\text { [30] }\end{array}$ & $\begin{array}{l}\text { Cross-sectional } \\
\text { survey }\end{array}$ & Chronic diseases & Thailand & $\begin{array}{l}\text { Transition from paediatric to adult care system for } \\
\text { patients with chronic illnesses }\end{array}$ \\
\hline $\begin{array}{l}\text { Ichiho, } 2013 \\
{[23]}\end{array}$ & $\begin{array}{l}\text { Review and } \\
\text { assessment }\end{array}$ & NCDs & $\begin{array}{l}\text { Federated } \\
\text { States of } \\
\text { Micronesia }\end{array}$ & Systems perspective on NCDs, including diabetes \\
\hline $\begin{array}{l}\text { Armstrong, } 2014 \\
{[35]}\end{array}$ & Case study & Tuberculosis & India & $\begin{array}{l}\text { Treating drug-resistant tuberculosis in a low-intensity } \\
\text { chronic conflict }\end{array}$ \\
\hline $\begin{array}{l}\text { McGuire, } 2014 \\
{[27]}\end{array}$ & Review & Cardiovascular diseases & $\begin{array}{l}\text { Low-resource } \\
\text { settings }\end{array}$ & $\begin{array}{l}\text { Medical devices and diagnostics for cardiovascular } \\
\text { diseases }\end{array}$ \\
\hline $\begin{array}{l}\text { Weigl, } 2014 \\
{[26]}\end{array}$ & Review & NCDs and chronic diseases & $\begin{array}{l}\text { Low-resource } \\
\text { settings }\end{array}$ & $\begin{array}{l}\text { Point-of-care diagnostics and their impact on care in } \\
\text { the age of the NCD and chronic disease epidemic }\end{array}$ \\
\hline $\begin{array}{l}\text { Doocy, } 2015 \\
{[33]}\end{array}$ & $\begin{array}{l}\text { Cross-sectional } \\
\text { survey }\end{array}$ & Chronic diseases & Jordan & $\begin{array}{l}\text { Prevalence and care-seeking for chronic diseases } \\
\text { among Syrian refugees }\end{array}$ \\
\hline $\begin{array}{l}\text { Knaul, } 2015 \\
{[24]}\end{array}$ & Review & Breast cancer & Mexico & $\begin{array}{l}\text { Example of breast cancer care to illustrate effective } \\
\text { universal health coverage along the chronic disease } \\
\text { continuum and across health systems functions }\end{array}$ \\
\hline $\begin{array}{l}\text { Lee, } 2015 \\
{[32]}\end{array}$ & Commentary & HIV & LMICs & $\begin{array}{l}\text { Transition from paediatric to adolescent to adult } \\
\text { healthcare settings for young HIV patients }\end{array}$ \\
\hline $\begin{array}{l}\text { Rabkin, } 2016 \\
{[34]}\end{array}$ & Review & HIV/chronic diseases & LMICs & $\begin{array}{l}\text { Lessons from HIV to address chronic diseases in } \\
\text { protracted emergencies }\end{array}$ \\
\hline $\begin{array}{l}\text { Silverman-Retana, } \\
2016 \text { [29] }\end{array}$ & $\begin{array}{l}\text { Cross-sectional } \\
\text { survey }\end{array}$ & $\begin{array}{l}\text { Diabetes mellitus/ } \\
\text { hypertension }\end{array}$ & Mexico & $\begin{array}{l}\text { Exploring transition of diabetes and hypertension } \\
\text { care among male prisoners }\end{array}$ \\
\hline $\begin{array}{l}\text { Nobrega, } 2017 \\
\text { [31] }\end{array}$ & Qualitative study & Chronic diseases & Brazil & $\begin{array}{l}\text { Evaluating continuity of care for children and } \\
\text { adolescents with chronic diseases in the healthcare } \\
\text { network }\end{array}$ \\
\hline
\end{tabular}

Group 2: Mentioning continuity or lack of continuity without a detailed definition

\begin{tabular}{|c|c|c|c|}
\hline $\begin{array}{l}\text { Greenberg, } 2002 \\
\text { [53] }\end{array}$ & Commentary & Chronic diseases & LMICs \\
\hline $\begin{array}{l}\text { Polanczyk, } 2009 \\
\text { [54] }\end{array}$ & Review & Coronary artery disease & Brazil \\
\hline $\begin{array}{l}\text { Suwanno, } 2009 \\
\text { [50] }\end{array}$ & $\begin{array}{l}\text { Cross-sectional } \\
\text { survey }\end{array}$ & Heart failure & Thailand \\
\hline $\begin{array}{l}\text { Ramli, } 2010 \\
\text { [36] }\end{array}$ & Review & Chronic heart failure & Malaysia \\
\hline $\begin{array}{l}\text { van Olmen, } 2011 \\
\text { [55] }\end{array}$ & Commentary & Chronic diseases & LICs \\
\hline $\begin{array}{l}\text { Lund, } 2012 \\
\text { [51] }\end{array}$ & Review & Mental health & South Africa \\
\hline $\begin{array}{l}\text { Bhojani, } 2013 \\
\text { [37] }\end{array}$ & $\begin{array}{l}\text { Qualitative } \\
\text { in-depth } \\
\text { interviews }\end{array}$ & Diabetes mellitus & India \\
\hline $\begin{array}{l}\text { Dasgupta, } 2014 \\
\text { [52] }\end{array}$ & Commentary & Chronic malnutrition & India \\
\hline $\begin{array}{l}\text { Ravaghi, } 2014 \\
\text { [38] }\end{array}$ & Qualitative SSIs & Diabetes mellitus & Iran \\
\hline $\begin{array}{l}\text { Atwine, } 2015 \\
\text { [47] }\end{array}$ & Qualitative FGDs & Diabetes mellitus & Uganda \\
\hline
\end{tabular}

A new perspective on global health assistance given health transitions and rise of chronic illnesses

Contemporary management and future perspectives for coronary artery disease

Predicting health status of a patient with heart failure

Management of chronic heart failure in primary care

Self-management facilitated by expert patient networks and smartphone technology

Mental health services

Patients perspective on managing diabetes care

Examining the burden of severe malnutrition (acute and chronic) and whether programmatic responses are consistent with epidemiologic realities

Provider's perspective on specialised care programme for diabetes

Health-seeking behaviour and use of traditional medicine among persons with type 2 diabetes 
Table 1 Study characteristics of included peer-reviewed articles $(n=55)$, divided by the five groups identified based on their use of the 'continuity of care' concept (Continued)

\begin{tabular}{|c|c|c|c|c|}
\hline $\begin{array}{l}\text { First author, } \\
\text { year }\end{array}$ & Study type & Condition & Location $^{a}$ & Main focus of the article \\
\hline $\begin{array}{l}\text { Hussein, } 2015 \\
\text { [39] }\end{array}$ & Review & Diabetes mellitus & Malaysia & Status of diabetes care and management \\
\hline $\begin{array}{l}\text { Mahomed, } 2015 \\
\text { [49] }\end{array}$ & $\begin{array}{l}\text { Quasi-experimental } \\
\text { study }\end{array}$ & Chronic diseases & South Africa & $\begin{array}{l}\text { A multifaceted intervention to improve the quality } \\
\text { of nurse clinical documentation for chronic patients } \\
\text { at primary care clinics }\end{array}$ \\
\hline $\begin{array}{l}\text { Maimela, } 2015 \\
\text { [40] }\end{array}$ & $\begin{array}{l}\text { Qualitative } \\
\text { study }\end{array}$ & Chronic diseases & South Africa & $\begin{array}{l}\text { Perceptions and perspectives of patients and } \\
\text { healthcare providers on chronic disease } \\
\text { management }\end{array}$ \\
\hline $\begin{array}{l}\text { Malan, 2015a } \\
{[41]}\end{array}$ & $\begin{array}{l}\text { Qualitative } \\
\text { interviews and } \\
\text { FGDs }\end{array}$ & NCDs & South Africa & $\begin{array}{l}\text { A situational analysis of training for behaviour } \\
\text { change counselling for primary care providers }\end{array}$ \\
\hline $\begin{array}{l}\text { Malan, 2015b } \\
{[42]}\end{array}$ & Qualitative study & NCDs & South Africa & $\begin{array}{l}\text { Experiences of primary care providers after a training } \\
\text { programme to offer brief behaviour change } \\
\text { counselling on risk factors for NCDs }\end{array}$ \\
\hline $\begin{array}{l}\text { Puspitasari, } 2015 \\
\text { [43] }\end{array}$ & $\begin{array}{l}\text { Qualitative } \\
\text { in-depth SSIs }\end{array}$ & NCDs & Indonesia & $\begin{array}{l}\text { Challenges in the management of chronic NCDs by } \\
\text { community pharmacists }\end{array}$ \\
\hline $\begin{array}{l}\text { Sellappans, } 2015 \\
\text { [48] }\end{array}$ & Qualitative FGDs & Chronic diseases & Malaysia & $\begin{array}{l}\text { Challenges faced by primary care physicians in a } \\
\text { teaching hospital when prescribing for patients with } \\
\text { chronic diseases }\end{array}$ \\
\hline $\begin{array}{l}\text { Wang, } 2015 \\
{[44]}\end{array}$ & $\begin{array}{l}\text { Household } \\
\text { survey }\end{array}$ & Chronic NCDs & Malawi & $\begin{array}{l}\text { Health-seeking behaviour and the related household } \\
\text { out-of-pocket expenditure for chronic NCDs }\end{array}$ \\
\hline $\begin{array}{l}\text { Khodaveisi, } 2017 \\
\text { [45] }\end{array}$ & $\begin{array}{l}\text { Randomised } \\
\text { clinical trial }\end{array}$ & Multiple sclerosis & Iran & $\begin{array}{l}\text { Effect of continuous care on the lifestyle of patients } \\
\text { with multiple sclerosis }\end{array}$ \\
\hline $\begin{array}{l}\text { Pelcastre-Villafuerte, } \\
2017 \text { [46] }\end{array}$ & $\begin{array}{l}\text { Ethnographical } \\
\text { review }\end{array}$ & $\begin{array}{l}\text { Diseases among } \\
\text { the elderly }\end{array}$ & Mexico & $\begin{array}{l}\text { A comprehensive healthcare model, interculturally } \\
\text { appropriate, designed to meet the needs of } \\
\text { indigenous older adults }\end{array}$ \\
\hline
\end{tabular}

Group 3: Researching continuity of care in HIV/AIDS programmes and scaling them up to support NCD management

\begin{tabular}{|c|c|c|c|c|}
\hline $\begin{array}{l}\text { Rabkin, 2011a } \\
{[61]}\end{array}$ & Commentary & HIV/NCDs & LMICs & $\begin{array}{l}\text { Leveraging HIV programmes to support NCD } \\
\text { services }\end{array}$ \\
\hline $\begin{array}{l}\text { Rabkin, } 2011 b \\
{[62]}\end{array}$ & Commentary & HIV/NCDs & LMICs & $\begin{array}{l}\text { Leveraging HIV programmes to support NCD } \\
\text { services }\end{array}$ \\
\hline $\begin{array}{l}\text { Rabkin, 2012a } \\
{[64]}\end{array}$ & Commentary & HIV/NCDs & LICS & $\begin{array}{l}\text { Leveraging HIV programmes to support NCD } \\
\text { services }\end{array}$ \\
\hline $\begin{array}{l}\text { Rabkin, 2012b } \\
\text { [63] }\end{array}$ & $\begin{array}{l}\text { Assessments and } \\
\text { pilot intervention }\end{array}$ & HIV/diabetes mellitus & $\begin{array}{l}\text { Ethiopia and } \\
\text { Swaziland }\end{array}$ & $\begin{array}{l}\text { Leveraging HIV programmes to support diabetes } \\
\text { services }\end{array}$ \\
\hline $\begin{array}{l}\text { Fujita, } 2015 \\
\text { [58] }\end{array}$ & $\begin{array}{l}\text { Collaborative } \\
\text { case study }\end{array}$ & HIV & $\begin{array}{l}6 \text { Asia and } \\
\text { Pacific countries }\end{array}$ & HIV service delivery model \\
\hline $\begin{array}{l}\text { Mkwinda, } 2016 \\
{[56]}\end{array}$ & $\begin{array}{l}\text { Qualitative } \\
\text { design }\end{array}$ & HIV & Malawi & $\begin{array}{l}\text { Exploring the needs of people living with HIV } \\
\text { concerning care received from primary caregivers } \\
\text { and palliative care nurses }\end{array}$ \\
\hline $\begin{array}{l}\text { Panditrao, } 2015 \\
{[60]}\end{array}$ & $\begin{array}{l}\text { Cross-sectional } \\
\text { survey }\end{array}$ & HIV & India & $\begin{array}{l}\text { Barriers to continued care among HIV-infected } \\
\text { women who were previously enrolled in a private } \\
\text { sector preventing mother-to-child transmission } \\
\text { programme }\end{array}$ \\
\hline $\begin{array}{l}\text { Kruk, } 2016 \\
{[59]}\end{array}$ & $\begin{array}{l}\text { Discrete choice } \\
\text { experiment }\end{array}$ & HIV & $\begin{array}{l}\text { Ethiopia and } \\
\text { Mozambique }\end{array}$ & $\begin{array}{l}\text { Identifying healthcare characteristics preferred by } \\
\text { HIV-infected women to promote treatment for a } \\
\text { lifetime }\end{array}$ \\
\hline $\begin{array}{l}\text { Ahonkhai, } 2017 \\
{[57]}\end{array}$ & $\begin{array}{l}\text { Cross-sectional } \\
\text { survey }\end{array}$ & HIV & Nigeria & Patient-centred medical home to provide HIV care \\
\hline
\end{tabular}

Group 4: Researching continuity of care in NCD management

\begin{tabular}{|c|c|c|c|c|}
\hline $\begin{array}{l}\text { Arevian, } 2005 \\
{[65]}\end{array}$ & Case study & Diabetes mellitus & Lebanon & $\begin{array}{l}\text { Collaborative practice model delivering care for } \\
\text { diabetes mellitus patients }\end{array}$ \\
\hline $\begin{array}{l}\text { Wei, 2008a } \\
\text { [67] }\end{array}$ & Case study & Diabetes mellitus & China & $\begin{array}{l}\text { Diabetes management programme and association } \\
\text { of continuity of care with clinical outcomes }\end{array}$ \\
\hline
\end{tabular}


Table 1 Study characteristics of included peer-reviewed articles $(n=55)$, divided by the five groups identified based on their use of the 'continuity of care' concept (Continued)

\begin{tabular}{|c|c|c|c|c|}
\hline $\begin{array}{l}\text { First author, } \\
\text { year }\end{array}$ & Study type & Condition & Location $^{a}$ & Main focus of the article \\
\hline $\begin{array}{l}\text { Hanafi, } 2015 \\
{[68]}\end{array}$ & $\begin{array}{l}\text { Retrospective } \\
\text { cohort study }\end{array}$ & Hypertension & Malaysia & $\begin{array}{l}\text { Impact of personal continuity of care on blood } \\
\text { pressure control in a university-based primary care } \\
\text { practice }\end{array}$ \\
\hline $\begin{array}{l}\text { Shi, 2015a } \\
\text { [73] }\end{array}$ & $\begin{array}{l}\text { Case-control } \\
\text { study }\end{array}$ & $\begin{array}{l}\text { Hypertension } \\
\text { /diabetes }\end{array}$ & China & $\begin{array}{l}\text { Impact of an integrated care delivery intervention on } \\
\text { healthcare seeking and outcomes for chronically ill } \\
\text { patients (i.e. with hypertension or diabetes) }\end{array}$ \\
\hline $\begin{array}{l}\text { Shi, 2015b } \\
{[71]}\end{array}$ & $\begin{array}{l}\text { Case- } \\
\text { comparison study }\end{array}$ & $\begin{array}{l}\text { Hypertension } \\
\text { /diabetes }\end{array}$ & China & $\begin{array}{l}\text { Examining which of the dominant primary care } \\
\text { delivery models (i.e. public community health } \\
\text { centres model, 'gate-keeper' CHC model or } \\
\text { hospital-owned CHC model) was most effective in } \\
\text { enhancing access to and quality of care for patients } \\
\text { with chronic diseases (i.e. with hypertension } \\
\text { or diabetes) }\end{array}$ \\
\hline $\begin{array}{l}\text { Tang, } 2015 \\
{[66]}\end{array}$ & Study design & Hypertension & China & $\begin{array}{l}\text { Study design of a clustered randomised controlled } \\
\text { trial to build and evaluate an integrated healthcare } \\
\text { system for chronic patients }\end{array}$ \\
\hline $\begin{array}{l}\text { Wei, } 2015 \\
\text { [72] }\end{array}$ & $\begin{array}{l}\text { Multistage } \\
\text { stratified } \\
\text { random survey }\end{array}$ & Chronic diseases & China & $\begin{array}{l}\text { Changes in perspectives of patients on quality of } \\
\text { primary care following the introduction of health } \\
\text { system reforms }\end{array}$ \\
\hline $\begin{array}{l}\text { Mwangome, } 2016 \\
\text { [75] }\end{array}$ & $\begin{array}{l}\text { Qualitative in- } \\
\text { depth interview }\end{array}$ & HIV/diabetes mellitus & Tanzania & $\begin{array}{l}\text { Perceptions, experiences and practice of care for } \\
\text { HIV and diabetes from the perspective of patients } \\
\text { and family caregivers }\end{array}$ \\
\hline $\begin{array}{l}\text { Ye, } 2016 \\
{[70]}\end{array}$ & Cohort study & Hypertension & China & $\begin{array}{l}\text { Effect of continuity of care on health-related quality } \\
\text { of life in adult patients with hypertension }\end{array}$ \\
\hline $\begin{array}{l}\text { Mwangome, } 2017 \\
{[74]}\end{array}$ & Qualitative study & Diabetes mellitus & Tanzania & $\begin{array}{l}\text { Perception of health providers on diabetes care } \\
\text { provision }\end{array}$ \\
\hline $\begin{array}{l}\text { Zhang, } 2017 \\
\text { [69] }\end{array}$ & $\begin{array}{l}\text { Clustered } \\
\text { randomised } \\
\text { controlled trial }\end{array}$ & Hypertension & China & $\begin{array}{l}\text { Effects of integrated chronic care models on } \\
\text { hypertension outcomes and spending }\end{array}$ \\
\hline \multicolumn{5}{|c|}{ Group 5: Measuring continuity of care with validated questionnaires } \\
\hline $\begin{array}{l}\text { Wei, 2008b } \\
{[76]}\end{array}$ & $\begin{array}{l}\text { Cross-sectional } \\
\text { survey }\end{array}$ & Diabetes mellitus & China & $\begin{array}{l}\text { Continuity of care in a community diabetes } \\
\text { programme }\end{array}$ \\
\hline $\begin{array}{l}\text { Vargas, } 2017 \\
{[77]}\end{array}$ & $\begin{array}{l}\text { Cross-sectional } \\
\text { survey }\end{array}$ & Chronic diseases & Columbia and Brazil & $\begin{array}{l}\text { Patient perceptions of continuity of healthcare and } \\
\text { associated factors }\end{array}$ \\
\hline
\end{tabular}

CHC community health center, FGDs focus group discussions, LICs low-income countries, LMICs low- and middle-income countries, NCDs non-communicable diseases, SSIs semi-structured interviews

aLocation could be: a country or a region or a setting

\section{Group 2. Mentioning continuity or lack of continuity without a detailed definition}

This group discussed the concept of $\mathrm{CoC}$ as a critical component of chronic disease management, in addition to its importance for long-term outcomes; it only appeared in the introduction or discussion sections without a specific definition. The 20 articles researched different levels of the healthcare system, including system analysis $(n=7)$, provider perspectives $(n=6)$, patient perspectives $(n=6)$, and both provider and patient perspectives $(n=1)$.

Table 2 provides a summary of how the concepts of $\mathrm{CoC}$ were used. Continuity, defined as care delivered over time, was mentioned in more than half the articles $(n=11)$ and was less likely to appear in articles using system analysis [36-46]. Four reports defined lack of continuity as care provided by several health providers [40, 43, 47, 48], while four focused on continuity as the quality of the patient-professional relationship [40, 41, 43, 45]. All papers focusing on the consistency of providers or the patient-professional relationship were reporting patient or provider perspectives. Eleven articles focused on continuity as the coordination of care across levels and disciplines [36$39,41,45,46,49-52]$; only two of the provider perspective articles discussed the informational component of continuity in particular [41, 49]. Finally, six articles discussed continuity with attention to adherence and compliance to treatment $[47,53,54]$, access and availability of care [40, 46], or quality of care [55]. Detailed segments retrieved from articles for each $\mathrm{CoC}$ item are available in Additional file 3. 
Table 2 Summary of the use of the 'continuity of care' concept among articles of Group 2 that mentioned continuity or lack of continuity without a detailed definition, divided by the articles' nature of analysis $(n=20)$

\begin{tabular}{llllll}
\hline Items of continuity of care & $\begin{array}{l}\text { Total } \\
(n=20)\end{array}$ & $\begin{array}{l}\text { System analysis } \\
(n=7)\end{array}$ & $\begin{array}{l}\text { Provider perspectives } \\
(n=6)\end{array}$ & $\begin{array}{l}\text { Patient perspectives } \\
(n=6)\end{array}$ & $\begin{array}{l}\text { Provider and patient } \\
\text { perspectives } \\
(n=1)\end{array}$ \\
\hline Longitudinal care (over time) & $11(55 \%)$ & $2(29 \%)$ & $4(67 \%)$ & $4(67 \%)$ & $1(100 \%)$ \\
Longitudinal care (consistency of personnel) & $4(20 \%)$ & $/$ & $1(17 \%)$ & $2(33 \%)$ & $1(100 \%)$ \\
Patient-provider relationship & $4(20 \%)$ & $/$ & $1(17 \%)$ & $2(33 \%)$ & $1(100 \%)$ \\
Coordinated care (across levels and disciplines) & $11(55 \%)$ & $4(57 \%)$ & $4(67 \%)$ & $3(50 \%)$ & $/$ \\
Other (access, quality and adherence) & $6(30 \%)$ & $3(43 \%)$ & $2(33 \%)$ & $/$ & $1(100 \%)$ \\
\hline
\end{tabular}

\section{Group 3. Researching CoC in HIV/AIDS programmes and scaling them up to support NCD management}

All identified articles defined $\mathrm{CoC}$ for HIV/AIDS patients as a follow-up to provide continuous life-long care [56-64]. Four empirical studies investigated $\mathrm{CoC}$ for HIV/AIDS patients from the patient perspective, and compared HIV service delivery models in different countries. These empirical studies mentioned other components of $\mathrm{CoC}$, for example, healthcare access, linkages across levels and services, and quality of care $[56-58,60]$, in addition to recording systems and documentation transitions $[57,58]$.

The remaining four articles were reviews on contributions of HIV programmes as models for interventions addressing NCDs, given that both are chronic [61-64]. They defined $\mathrm{CoC}$ as "coordination of services over time and across disciplines" [64]; other dimensions of $\mathrm{CoC}$ were used but not explicitly mentioned in their definition, such as consistency of personnel [61] and patientprofessional relationships [61, 62, 64]. The authors also stressed that approaches to integrate services for HIV and other diseases might vary: "In some contexts, integration of services for all chronic diseases, HIV and NCD alike, may be the best approach. In others, programs may not be integrated at the point of service but may draw upon similar systems, from monitoring and evaluation to procurement" [62]. The authors provided practical examples for successful HIV interventions with chronic care components relevant for other NCDs, such as counselling and adherence support, standardised treatment protocols, and task-shifting/task-sharing [61, 62].

\section{Group 4. Researching CoC in NCD management}

This group includes articles that mentioned $\mathrm{CoC}$ in their objectives or methods or as part of a NCD programme or intervention. In six articles, four interventions were described that improve $\mathrm{CoC}$ for patients with chronic diseases [65-70]. Three articles investigated one intervention in China, one discussing a proposal [66] and two on empirical datasets $[69,70]$. Three other interventions were implemented at the primary healthcare level in China using two models, namely Starfield's model of primary care and the Primary Care Assessment Tool; both have components of $\mathrm{CoC}$ [71-73]. Finally, two qualitative studies investigated $\mathrm{CoC}$ in the Tanzanian Health System at the patient and provider levels, based on WHO's ICCC Framework [74, 75].

These 11 articles can be divided into two groups based on their objectives, namely those that aim to study $\mathrm{CoC}$ concerning access or quality $(n=6 ; 55 \%)[65,66,71,72,74,75]$ and those aiming to investigate the impact of $\mathrm{CoC}$ on outcomes $(n=5 ; 45 \%)$ such as clinical outcomes $[67,68]$, healthcare seeking and clinical outcomes [73], healthcare spending and clinical outcomes, [69] or quality of life [70].

Table 3 provides a summary of how these articles used the concepts of $\mathrm{CoC}$. All 11 articles included a component for longitudinal care over time with one healthcare setting or provider as a primary point of contact (e.g. community health centre, personal doctor or public health officer at a clinic/centre). Two interventions facilitated patients' getting scheduled appointments.

The second component of CoC usually included coordinated care across levels, for example, using team collaboration, standardised guidelines, referrals and clinical pathways, besides an informational component using medical records and information sharing, which appeared in the qualitative study. In most articles, there was no measurement or comprehensive explanation of aspects of coordinated care.

Articles that used primary healthcare models investigated the patient-provider relationship using proxy questions, for example, "Healthcare professionals always encourage you to ask questions" [71, 73]. Both patients and providers in the qualitative studies discussed the nature of their relationship, especially its role in patient education, improvement of illness management skills, and encouragement of self-management. Further information on definitions and measurements used in each article is given in Additional file 3.

\section{Group 5. Measuring $\mathrm{COC}$ with validated questionnaires}

Two articles used tools to measure the $\mathrm{CoC}$ from the patient's perspective [76, 77]. One developed and validated a tool, while the other used an existing 
Table 3 Summary of the use of the 'continuity of care' concept among articles of Group 4 that researched continuity of care in non-communicable disease management, divided by the articles' type and use of conceptual models ( $n=11$, two articles of same study)

\begin{tabular}{|c|c|c|c|c|}
\hline Characteristics & $\begin{array}{l}\text { Total } \\
(n=10)\end{array}$ & $\begin{array}{l}\text { Intervention } \\
(n=5)\end{array}$ & $\begin{array}{l}\text { PHC model } \\
(n=3)\end{array}$ & $\begin{array}{l}\text { ICCC framework } \\
(n=2)\end{array}$ \\
\hline \multicolumn{5}{|l|}{ Data collection level } \\
\hline System & $4(40 \%)$ & $4(80 \%)$ & 0 & 0 \\
\hline Providers & $1(10 \%)$ & 0 & 0 & $1(50 \%)$ \\
\hline Patients & $5(50 \%)$ & $1(20 \%)$ & $3(100 \%)$ & $1(50 \%)$ \\
\hline Access & $8(80 \%)$ & $3(60 \%)$ & $3(100 \%)$ & $2(100 \%)$ \\
\hline Quality & $6(60 \%)$ & $1(20 \%)$ & $3(100 \%)$ & $2(100 \%)$ \\
\hline \multicolumn{5}{|l|}{ Measurements } \\
\hline Quantitative measure for $\mathrm{CoC}^{\mathrm{a}}$ & $8(80 \%)$ & $5(100 \%)$ & $3(100 \%)$ & NA \\
\hline Disease outcome & $4(40 \%)$ & $4(80 \%)$ & 0 & NA \\
\hline Other outcomes ${ }^{b}$ & $3(30 \%)$ & $1(20 \%)$ & $2(67 \%)$ & NA \\
\hline \multicolumn{5}{|l|}{ Intervention components for providers } \\
\hline Training for providers & $5(50 \%)$ & $3(60 \%)$ & $2(67 \%)$ & NA \\
\hline Financial incentives & $3(30 \%)$ & $2(40 \%)$ & $1(33 \%)$ & NA \\
\hline \multicolumn{5}{|l|}{ Items of continuity of care } \\
\hline Longitudinal care (over time) & $10(100 \%)$ & $5(100 \%)$ & $3(100 \%)$ & $2(100 \%)$ \\
\hline Longitudinal care (consistency of personnel) & $6(60 \%)$ & $4(80 \%)$ & $2(67 \%)$ & / \\
\hline Patient-provider relationship & $6(60 \%)$ & $2(40 \%)$ & $2(67 \%)$ & $2(100 \%)$ \\
\hline Coordinated care (across levels and disciplines) & $7(70 \%)$ & $3(60 \%)$ & $3(100 \%)$ & $1(50 \%)$ \\
\hline Coordinated care (informational component) & $6(60 \%)$ & $3(60 \%)$ & $2(67 \%)$ & $1(50 \%)$ \\
\hline
\end{tabular}

CoC continuity of care, ICCC innovative care for chronic conditions, NA not available, PHC primary healthcare

${ }^{a}$ Examples were clinic utilisation, Likert scale, Usual Provider Continuity Index, Continuity of Care Index

bexamples were satisfaction, cost and 'subjective' health improvement, and quality of life

questionnaire. The instruments used two different definitions and frameworks for $\mathrm{CoC}$.

Wei et al. [76] used Donaldson's CoC definition based on agency theory [78], namely "The degree to which health care activities are structured to increase information transfer and goal alignment between providers and patients to minimise agency loss". This assessment instrument for diabetic patients used two validated tools - the Primary Care Assessment Survey, after dropping 'access', and the Summary of Diabetes Self-care Activities Measure, comprising 46 items using a Likert-scale in the two sections of information transfer and goal alignment. The new tool was compared to a conventional measure of $\mathrm{CoC}$, 'Concentration of Care' defined as "the duration of care between the patient and his/her primary doctor and the proportion of total visits to the primary doctor" [76].

Vargas et al. [77] determined the level of $\mathrm{CoC}$ perceived by users and explored influencing factors in two countries with different health systems (Colombia and Brazil). They used the $\mathrm{CoC}$ definition of Reid et al., namely "the patient's experience of care over time as connected and coherent with his or her health needs and personal circumstances. In other words, CoC refers to the perception and experience of an individual patient, as opposed to the providers' perspective, which would be defined as coordination of care" [79]. According to this definition, there are three types of $\mathrm{CoC}$, namely (1) continuity of information, or the perception of transfer of clinical information across levels of care; (2) continuity of clinical management, or the perception of care coherence across levels of care; and (3) relational continuity, or the perception of an ongoing doctor-patient relationship.

The researchers used a validated tool, the CCAENAV questionnaire (Cuestionario de Continuidad Asistencial Entre Niveles de Atencion, in Spanish). The care continuity scale had four synthetic indexes for each of the following sub-scales: information transfer, care coherence, patientprimary care doctor relationship, and patient-secondary care doctor relationship, in addition to a separate item outside the scale for the consistency of health professionals. The questionnaire included 14 questions with a Likert-scale format.

There were five common themes in the questionnaires of Wei et al. [76] and Vargas et al. [77], namely (1) the consistency of health professionals; (2) primary care doctor's knowledge of patient's medical/clinical history; (3) primary care doctor provides counselling to patients using effective communication; (4) trust between 
provider and patient; and (5) coherence in treatment provided by primary care doctors and specialists reflecting collaboration across care levels.

The questionnaire of Wei et al. [76] included questions regarding the interpersonal relationship between provider and patients. For example, the primary care doctor's knowledge of the patient's responsibilities at home or work. A detailed comparison between the questionnaires of Wei et al. [76] and Vargas et al. [77] is available in Additional file 3.

\section{Discussion}

The literature discussing $\mathrm{CoC}$ in LMICs has increased over the last two decades. Most articles suggested $\mathrm{CoC}$ as a priority for problems of people with chronic conditions but rarely specified a definition for $\mathrm{CoC}$. In many cases, the words 'continuum' and 'continuity' were used interchangeably. Linguistically, the Oxford Dictionary defines continuity as "[t]he unbroken and consistent existence or operation of something over time; a state of stability and the absence of disruption; a connection or line of development with no sharp breaks" [80], and continuum as "[a] continuous sequence in which adjacent elements are not perceptibly different from each other, but the extremes are quite distinct" [81]. The definition of continuum corresponds with looking at care as a continuum provided from birth to end of life, or as services provided through the course of disease with a consecutive sequence of primary prevention, secondary prevention or early detection (e.g. screening), diagnosis, treatment, management and complication detection, survivorship and rehabilitation care, to palliative and end-of-life care. In this sense, although care as a continuum can help to evaluate the accessibility of the health system, it would be less critical for the patient's perspective regarding their healthcare needs.

The concept of $\mathrm{CoC}$ was defined and used differently in various articles, complicating any synthesis of evidence related to $\mathrm{CoC}$ and its impact on long-term care. This observation is similar to the findings of a literature review that focused on research from high-income countries, which found that definitions of $\mathrm{CoC}$ and related concepts varied over time, leading to confusion [8, 82]. To avoid this ambiguity, we will use the definition of $\mathrm{CoC}$ as the provision of coordinated care and services over time and across levels and disciplines, which is coherent with the patient's health needs and personal circumstances. This definition combines three key components of $\mathrm{CoC}$ - longitudinal care, the patient-provider relationship and coordinated care, including information management. This definition includes all the above-mentioned shared themes for long-term care. Additionally, it includes contextualisation of $\mathrm{CoC}$ based on the patient's and provider's characteristics and service organisation [10,83].

At the primary healthcare level, $\mathrm{CoC}$ mostly means responding to the needs of patients with chronic or life-long conditions. The patient's needs for $\mathrm{CoC}$ are similar in limited-resource and high-income settings. However, more research and policy need to focus on developing interventions that can be implemented by leveraging available resources within the health system. For example, many LMICs face an additional challenge of meeting the health needs of chronic patients in mobile populations (e.g. displaced, refugees) or emergency settings. Secondly, although $\mathrm{CoC}$ is mostly applied to NCDs, it also applies to chronic communicable diseases and chronic malnutrition. Therefore, it is better to describe $\mathrm{CoC}$ within the context of long-term care, providing an opportunity for health policy and systems to combine or integrate experiences and resources to tackle both communicable diseases and NCDs instead of competing for funds. Thirdly, studies defining $\mathrm{CoC}$ as care experienced by individuals need to consider the roles of patients, providers, systems and policy in implementing and achieving CoC. Fourthly, research on $\mathrm{CoC}$ occasionally assumes that health services are accessible to patients. To fully understand $\mathrm{CoC}$ and translate this understanding into policy, it is essential to look at $\mathrm{CoC}$ within the overall context of health services, especially regarding access and quality.

The definitions and components of $\mathrm{CoC}$ used in research in LMICs show similarities and differences. There is a shared understanding that $\mathrm{CoC}$ contains a component for longitudinal care as repeated and regular visits to health services over time, perhaps best provided at the lowest level, i.e. primary healthcare. Longitudinal care may also include a component for patients to interact with as few providers as possible, which may be harder to achieve when primary healthcare services are not easily accessible or do not satisfy minimum quality standards. Despite the importance of the patient-provider relationship, it was rarely included in the definitions of $\mathrm{CoC}$ used, and only mentioned during patient's interviews with a primary focus on the provider's role in encouraging self-management. The nature of the patient-provider relationship may include three characteristics, namely familiarity, so providers are able to consider the patient's personal and social context; patient's trust in their providers; and knowledge co-production, which leads to better health literacy and self-management practices.

The second most frequently mentioned component for $\mathrm{CoC}$ was coordinated care, which could take place within one level or across different levels in the health system; it could be achievable through referrals and back-referrals. In many resource-constrained settings, it 


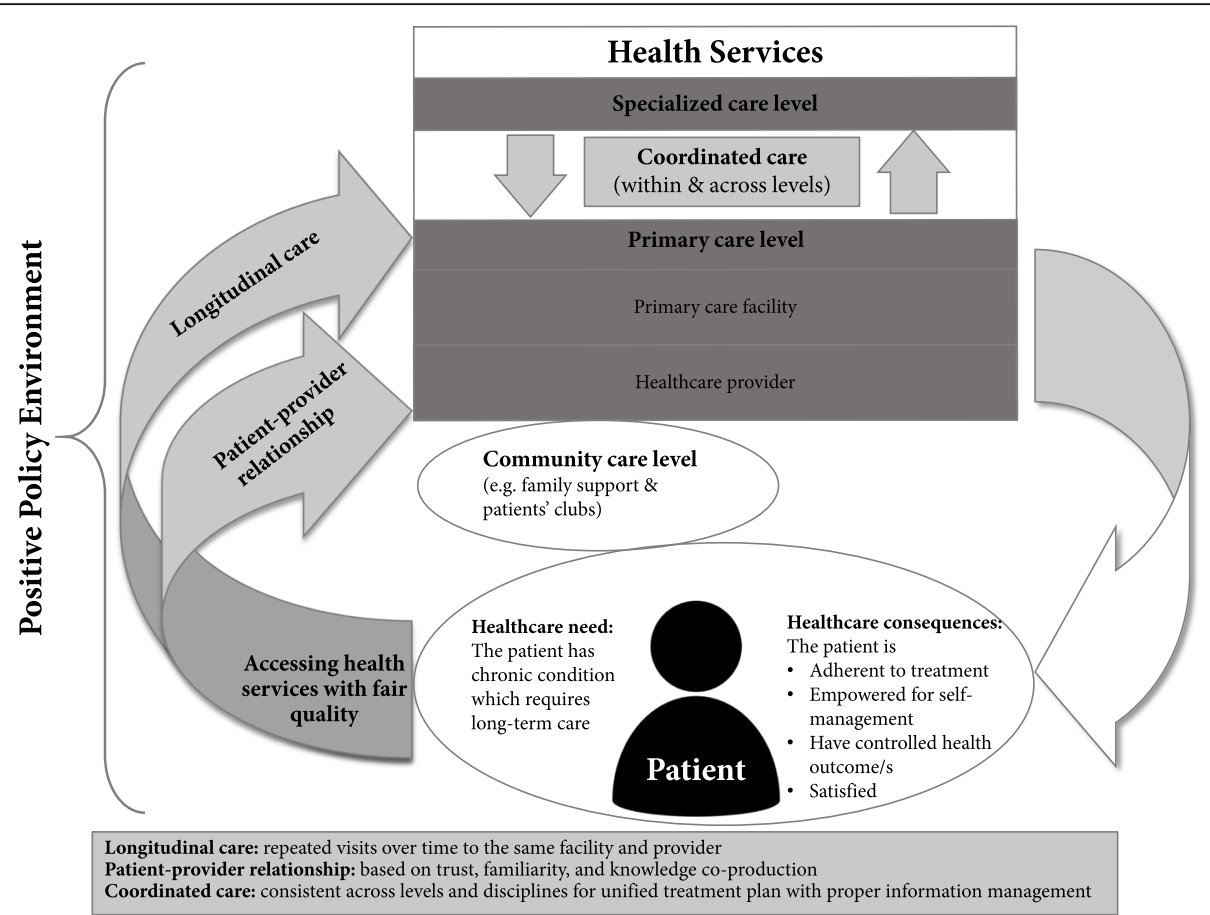

Fig. 1 Conceptual framework for continuity of care and its three components as relevant to primary healthcare in a global context (including resource-constrained settings), adapted from WHO's ICCC [7] and Salisbury 2009 [86]

is not easy to implement team-based collaboration, but coordinated care should provide patients with consistent, unified treatment plans and medications, especially across levels, based on guidelines or management protocols. Another essential characteristic of coordinated care is patient information management, whether written or electronic, with the aims of record-keeping over time to accumulate knowledge of prior visits and sharing or transferring information within and across levels.

Figure 1 illustrates the findings concerning $\mathrm{CoC}$ definitions and components, revealing the circular nature of long-term care. This framework can be useful in global health research, policy and planning. Even if the use of $\mathrm{CoC}$ focuses on one component, describing and understanding this framework ensures acknowledgement of other components and key contextual factors.

Interventions to promote longitudinal care may include paper-based or electronic appointment systems for scheduled follow-up, using appointment books, on-site medical records, or mobile phone applications. Nurturing a positive patient-provider relationship requires counselling during a consultation, and building partnerships with communities through peer educators and patient support groups. Promotion of mobile phone apps and text reminders may facilitate retention in care. Interventions to encourage information management include easy to carry or access patient-held records, possibly using mobile phone applications. To increase the consistency of care, standardised treatment protocols are crucial, customised to the context of health service delivery and health insurance. Other interventions to facilitate coordinated care may include task-shifting or task-sharing towards more available caregivers.

Finally, to achieve longitudinal care and a positive patient-provider relationship, most articles focused on strengthening primary healthcare, ensuring access, and the inclusion of chronic care in basic health benefit packages. These approaches build upon the Sustainable Development Goals, WHO's global strategies towards people-centred and integrated health services [3], and universal health coverage [84]. The potential strategies target all building blocks of the health system, such as governance, financing, workforce, service delivery, information management, and medical products/technology. Current research and policy in resource-constrained settings aiming to identify and implement best practices to strengthen primary healthcare and extend universal health coverage should consider their role in achieving $\mathrm{CoC}$, while providing a precise definition of the concept and its components.

The review has limitations. First, it involved one search engine (i.e. PubMed); however, it is unlikely that essential publications were missed given the review's exploratory nature. Second, the processes of data abstraction and extraction were performed by a single 
researcher. However, the use of inductive thematic analysis matches a more robust strategy of a single researcher conducting data extraction at two separate time points [85].

In conclusion, those using the concept of $\mathrm{CoC}$ in research or policy must provide an explicit definition in their reports. A suggested definition of $\mathrm{CoC}$ is the provision of coordinated care and services over time and across levels and disciplines, which is coherent with patient's health needs and personal circumstances. This definition covers three key components for $\mathrm{CoC}$ - longitudinal care (repeated visits over time), the nature of the patient-provider relationship (based on trust, familiarity and knowledge co-production), and coordinated care (consistent across levels and disciplines for a unified treatment plan with proper information management). This scoping review suggests a framework for $\mathrm{CoC}$ that could be operational for LMICs, acknowledging its multiple components and contextual factors, particularly access and quality. However, there is a need for further research and guidance to clarify and extend this definition and framework for emergency settings where $\mathrm{CoC}$ and its components are hard to achieve, especially repeated visits and positive patient-provider relationships, because of the limited patient mobility. The global priorities of strengthening primary healthcare and extending universal health coverage should consider interventions to achieve $\mathrm{CoC}$, especially for patients with chronic conditions.

\section{Additional files}

Additional file 1: Continuity of care concepts. Definitions for continuity of care with focus on primary healthcare settings (DOCX $87 \mathrm{~kb}$ )

Additional file 2: Search strategy. Detailed tables on the search terms and strategy used in PubMed (DOC $43 \mathrm{~kb}$ )

Additional file 3: Extra tables. Detailed segments retrieved for three of the five identified groups of articles. (DOC $187 \mathrm{~kb}$ )

\section{Abbreviations}

CCM: Chronic Care Model; CoC: continuity of care; ICCC: Innovative Care for Chronic Conditions; LMICs: low- and middle-income countries; NCDs: noncommunicable diseases

\section{Acknowledgements}

The authors would like to thank Dima Meiqari for her inputs on the visualisation of the framework. Alison Fisher provided editing assistance.

\section{Funding}

The Erasmus Mundus Joint Doctorate Fellowship, Specific Grant Agreement 2014-0681, of which LM is a beneficiary, supported this review. The funding agency had no role in study design, analysis or preparation of the manuscript.

\section{Availability of data and materials}

All data generated or analysed during this study are included in this published article and its supplementary information files.

\section{Authors' contributions}

LM conceived, designed, undertook the review, and wrote the initial draft. TA and PW supported the synthesis and interpretation of results. All authors contributed to the revisions and approved the final manuscript.

Ethics approval and consent to participate

Not applicable.

Consent for publication

Not applicable.

\section{Competing interests}

The authors declare that they have no competing interests.

\section{Publisher's Note}

Springer Nature remains neutral with regard to jurisdictional claims in published maps and institutional affiliations.

\section{Author details}

${ }^{1}$ Athena Institute for Research on Innovation and Communication in Health and Life Sciences, Faculty of Sciences, Vrije Universiteit Amsterdam, De Boelelaan 1085, $1081 \mathrm{HV}$ Amsterdam, The Netherlands. ${ }^{2}$ Department of Public Health, Institute of Tropical Medicine, Antwerp, Belgium. ${ }^{3}$ Médecins Sans Frontières, Operational Centre Geneva (MSF-OCG), Geneva, Switzerland.

${ }^{4}$ Guelph International Health Consulting, Amsterdam, The Netherlands.

Received: 8 October 2018 Accepted: 14 February 2019

Published online: 07 March 2019

\section{References}

1. Wang $\mathrm{H}$, Abajobir AA, Abate $\mathrm{KH}$, Abbafati C, Abbas KM, Abd-Allah F, et al. Global, regional, and national under-5 mortality, adult mortality, age-specific mortality, and life expectancy, 1970-2016: a systematic analysis for the Global Burden of Disease Study. Lancet. 2016;390(10100):1084-150.

2. Hay SI, Abajobir AA, Abate KH, Abbafati C, Abbas KM, Abd-Allah F, et al. Global, regional, and national disability-adjusted life-years (DALYs) for 333 diseases and injuries and healthy life expectancy (HALE) for 195 countries and territories, 1990-2016: a systematic analysis for the Global Burden of Disease Study. Lancet. 2016;390:1260-344.

3. World Health Organization. WHO Global Strategy on People-centred and Integrated Health Services. Geneva: WHO, Service Delivery and Safety; 2015. http://www.who.int/servicedeliverysafety/areas/people-centred-care/globalstrategy/en/. Accessed 25 Feb 2019

4. Nolte E, McKee M, editors. Caring for People with Chronic Conditions: A Health System Perspective. European Observatory on Health Systems and Policies Series. Open University Press \& World Health Organization; 2008. http://www.euro.who.int/_data/assets/pdf_file/0006/96468/E91878.pdf. Accessed 25 Feb 2019.

5. Robinson HM, Hort K. Non-communicable diseases and health systems reform in low-and-middle-income countries. Pac Health Dialog. 2012;18(1): 179-90.

6. Wagner EH. Chronic disease management: what will it take to improve care for chronic illness? Eff Clin Pract. 1998; 1(1):2-4

7. World Health Organization. Innovative Care for Chronic Conditions: Building Blocks for Action. Geneva: WHO; 2002.

8. Uijen AA, Schers HJ, Schellevis FG, van den Bosch WJHM. How unique is continuity of care? A review of continuity and related concepts. Fam Pract. 2012:29(3):264-71:

9. Walt G, Shiffman J, Schneider H, Murray SF, Brugha R, Gilson L. 'Doing' health policy analysis: methodological and conceptual reflections and challenges. Health Policy Plan. 2008;23(5):308-17.

10. Christakis DA. Continuity of care: process or outcome? Ann Fam Med. 2003:1(3):131-3.

11. Lall $D$, Engel N, Devadasan N, Horstman $K$, Criel B. Models of care for chronic conditions in low/middle-income countries: a 'best fit' framework synthesis. BMJ Glob Health. 2018;3(6):e001077.

12. Haggerty JL, Reid RJ, Freeman GK, Starfield BH, Adair CE, McKendry R. Continuity of care: a multidisciplinary review. BMJ. 2003;327(7425):1219-21.

13. Saultz JW, Lochner J. Interpersonal continuity of care and care outcomes: a critical review. Ann Fam Med. 2005;3(2):159-66. 
14. van Servellen G, Fongwa M, Mockus D'EE. Continuity of care and quality care outcomes for people experiencing chronic conditions: a literature review. Nurs Health Sci. 2006;8(3):185-95.

15. Van Walraven C, Oake N, Jennings A, Forster AJ. The association between continuity of care and outcomes: a systematic and critical review. J Eval Clin Pract. 2010;16(5):947-56.

16. Cabana MD, Jee SH. Does continuity of care improve patient outcomes. J Fam Pr. 2004;53(12):974-80.

17. Sturmberg JP. Continuity of care: a systems-based approach. Asia Pac Fam Med. 2003;2(3):136-42.

18. Colquhoun HL, Levac D, O'Brien KK, Straus S, Tricco AC, Perrier L, et al. Scoping reviews: time for clarity in definition, methods, and reporting. J Clin Epidemiol. 2014;67(12):1291-4.

19. Levac D, Colquhoun H, O'Brien KK. Scoping studies: advancing the methodology. Implement Sci. 2010;5:69.

20. Daudt HM, van Mossel C, Scott SJ. Enhancing the scoping study methodology: a large, inter-professional team's experience with Arksey and O'Malley's framework. BMC Med Res Methodol. 2013;13:48.

21. Arksey H, O'Malley L. Scoping studies: towards a methodological framework. Int J Soc Res Methodol. 2005;8(1):19-32.

22. Ouzzani M, Hammady H, Fedorowicz Z, Elmagarmid A. Rayyan - a web and mobile app for systematic reviews. Syst Rev. 2016;5(1):210.

23. Ichiho HM, Anson R, Keller E, Lippwe K, Aitaoto N. An assessment of noncommunicable diseases, diabetes, and related risk factors in the Federated States of Micronesia, State of Pohnpei: a systems perspective. Hawaii J Med Public Health. 2013;72(5):49-56.

24. Knaul FM, Bhadelia A, Atun R, Frenk J. Achieving effective universal health coverage and diagonal approaches to care for chronic illnesses. Health Aff. 2015;34(9):1514-22.

25. Mayige M, Kagaruki G, Ramaiya K, Swai A. Non communicable diseases in Tanzania: a call for urgent action. Tanzan J Health Res. 2011;13(5):378-86.

26. Weigl BH, Neogi T, McGuire H. Point-of-care diagnostics in low-resource settings and their impact on care in the age of the noncommunicable and chronic disease epidemic. J Lab Autom. 2014;19(3):248-57.

27. McGuire H, Weigl BH. Medical devices and diagnostics for cardiovascular diseases in low-resource settings. J Cardiovasc Transl Res. 2014:7(8):737-48.

28. Robles SC. A public health framework for chronic disease prevention and control. Food Nutr Bull. 2004;25(2):194-9.

29. Silverman-Retana O, Servan-Mori E, Lopez-Ridaura R, Bautista-Arredondo S. Diabetes and hypertension care among male prisoners in Mexico City: exploring transition of care and the equivalence principle. Int J Public Health. 2016;61(6):651-9.

30. Pakdeeprom B, In-Iw S, Chintanadilok N, Wichiencharoen DK, Manaboriboon B. Promoting factors for transition readiness of adolescent chronic illnesses: experiences in Thailand. J Med Assoc Thai. 2012:95(8):1028-34.

31. Nóbrega VM, Silva MEA, Fernandes LTB, Viera CS, Reichert APS, Collet N. Chronic disease in childhood and adolescence: continuity of care in the Health Care Network. Rev Esc Enferm U P. 2017;51:e03226.

32. Lee S, Hazra R. Achieving 90-90-90 in paediatric HIV: adolescence as the touchstone for transition success. J Int AIDS Soc. 2015;18:20257.

33. Doocy S, Lyles E, Roberton T, Akhu-Zaheya L, Oweis A, Burnham G. Prevalence and care-seeking for chronic diseases among Syrian refugees in Jordan. BMC Public Health. 2015;15:1097.

34. Rabkin M, Fouad FM, El-Sadr WM. Addressing chronic diseases in protracted emergencies: Lessons from HIV for a new health imperative. Glob Public Health. 2018;13(2):227-33.

35. Armstrong E, Das M, Mansoor H, Babu RB, Isaakidis P. Treating drugresistant tuberculosis in a low-intensity chronic conflict setting in India. Confl Health. 2014:8:25.

36. Ramli A, Jackson B, Toh C, Ambigga D, Piterman L. Management of chronic heart failure in primary care: what evidence do we have for heart failure with preserved systolic function? Malays Fam Physician. 2010:5(2):68-76.

37. Bhojani U, Mishra A, Amruthavalli S, Devadasan N, Kolsteren P, De Henauw $\mathrm{S}$, et al. Constraints faced by urban poor in managing diabetes care: patients' perspectives from South India. Glob Health Action. 2013;6:22258.

38. Ravaghi H, Sajadi HS, Ghotbi M, Sarvarizadeh S, Sharbafchizadeh N, Kermanchi J. Evaluation of an urban phase of the specialized care program for diabetes in Iran: providers' perspectives. Int J Prev Med. 2014:5(8):1013-22

39. Hussein Z, Taher SW, Gilcharan Singh HK, Chee Siew Swee W. Diabetes care in Malaysia: problems, new models, and solutions. Ann Glob Health. 2015; 81(6):851-62.
40. Maimela E, Van Geertruyden J-P, Alberts M, Modjadji SEP, Meulemans H, Fraeyman J, et al. The perceptions and perspectives of patients and health care providers on chronic diseases management in rural South Africa: a qualitative study. BMC Health Serv Res. 2015;15:143.

41. Malan Z, Mash B, Everett-Murphy K. A situational analysis of training for behaviour change counselling for primary care providers, South Africa. Afr J Prim Health Care Fam Med. 2015;7(1):731.

42. Malan Z, Mash R, Everett-Murphy K. Qualitative evaluation of primary care providers experiences of a training programme to offer brief behaviour change counselling on risk factors for non-communicable diseases in South Africa. BMC Fam Pract. 2015;16:101.

43. Puspitasari HP, Aslani P, Krass I. Challenges in the management of chronic noncommunicable diseases by Indonesian community pharmacists. Pharm Pract. 2015;13(3):578

44. Wang Q, Brenner S, Leppert G, Banda TH, Kalmus O, De Allegri M. Health seeking behaviour and the related household out-of-pocket expenditure for chronic non-communicable diseases in rural Malawi. Health Policy Plan. 2015;30(2):242-52

45. Khodaveisi M, Ashtarani F, Beikmoradi A, Mohammadi N, Mahjub $\mathrm{H}$, Mazdeh $\mathrm{M}$, et al. The effect of continuous care on the lifestyle of patients with multiple sclerosis: a randomized clinical trial. Iran J Nurs Midwifery Res. 2017;22(3):225-31.

46. Pelcastre-Villafuerte BE, Meneses-Navarro S, Ruelas-González MG, ReyesMorales H, Amaya-Castellanos A, Taboada A. Aging in rural, indigenous communities: an intercultural and participatory healthcare approach in Mexico. Ethn Health. 2017;22(6):610-30.

47. Atwine F, Hultsjö S, Albin B, Hjelm K. Health-care seeking behaviour and the use of traditional medicine among persons with type 2 diabetes in southwestern Uganda: a study of focus group interviews. Pan Afr Med J. 2015;20:76.

48. Sellappans R, Lai PSM, Ng CJ. Challenges faced by primary care physicians when prescribing for patients with chronic diseases in a teaching hospital in Malaysia: a qualitative study. BMJ Open. 2015;5(8):e007817.

49. Mahomed OH, Naidoo S, Asmall S, Taylor M. Improving the quality of nurse clinical documentation for chronic patients at primary care clinics: a multifaceted intervention. Curationis. 2015;38(1):1497.

50. Suwanno J, Petpichetchian W, Riegel B, Issaramalai S-A. A model predicting health status of patients with heart failure. J Cardiovasc Nurs. 2009;24(2):118-26.

51. Lund C, Petersen I, Kleintjes S, Bhana A. Mental health services in South Africa: taking stock. Afr J Psychiatry. 2012;15(6):402-5.

52. Dasgupta R, Sinha D, Yumnam V. Programmatic response to malnutrition in India, room for more than one elephant. Indian Pediatr. 2014;51(11):863-8.

53. Greenberg HM, Farmer RG. Global health assistance: a new perspective. Ann Noninvasive Electrocardiol. 2002;7(1):73-7.

54. Polanczyk CA, Ribeiro JP. Coronary artery disease in Brazil: contemporary management and future perspectives. Heart Br Card Soc. 2009;95(11):870-6.

55. van Olmen J, Ku GM, Bermejo R, Kegels G, Hermann K, Van Damme W. The growing caseload of chronic life-long conditions calls for a move towards full self-management in low-income countries. Glob Health. 2011;7:38.

56. Mkwinda E, Lekalakala-Mokgele E. Palliative care needs in Malawi: care received by people living with HIV. Curationis. 2016;39(1):1664.

57. Ahonkhai AA, Onwuatuelo I, Regan S, Adegoke A, Losina E, Banigbe B, et al. The patient-centered medical home: a reality for HIV care in Nigeria. Int J Qual Health Care. 2017;29(5):654-61.

58. Fujita M, Poudel KC, Green K, Wi T, Abeyewickreme I, Ghidinelli M, et al. HIV service delivery models towards "Zero AIDS-related Deaths": a collaborative case study of 6 Asia and Pacific countries. BMC Health Serv Res. 2015;15:176.

59. Kruk ME, Riley PL, Palma AM, Adhikari S, Ahoua L, Arnaldo C, et al. How can the health system retain women in HIV treatment for a lifetime? A discrete choice experiment in Ethiopia and Mozambique. PLoS One. 2016;11(8):e0160764.

60. Panditrao M, Darak S, Jori V, Kulkarni S, Kulkarni V. Barriers associated with the utilization of continued care among HIV-infected women who had previously enrolled in a private sector PMTCT program in Maharashtra. India. AIDS Care. 2015;27(5):642-8.

61. Rabkin M, El-Sadr WM. Why reinvent the wheel? Leveraging the lessons of HIV scale-up to confront non-communicable diseases. Glob Public Health. 2011:6(3):247-56.

62. Rabkin M, Nishtar S. Scaling up chronic care systems: leveraging HIV programs to support noncommunicable disease services. J Acquir Immune Defic Syndr. 2011;57:S87-90. 
63. Rabkin M, Melaku Z, Bruce K, Reja A, Koler A, Tadesse Y, et al. Strengthening health systems for chronic care: leveraging HIV programs to support diabetes services in Ethiopia and Swaziland. J Trop Med. 2012;2012:137460

64. Rabkin M, Kruk ME, El-Sadr WM. HIV, aging and continuity care: strengthening health systems to support services for noncommunicable diseases in low-income countries. AIDS. 2012;26:577-83.

65. Arevian M. The significance of a collaborative practice model in delivering care to chronically ill patients: a case study of managing diabetes mellitus in a primary health care center. J Interprof Care. 2005;19(5):444-51.

66. Tang W, Sun X, Zhang Y, Ye T, Zhang L. How to build and evaluate an integrated health care system for chronic patients: study design of a clustered randomised controlled trial in rural China. Int J Integr Care. 2015;15:e007

67. Wei X, Barnsley J, Zakus D, Cockerill R, Glazier R, Sun X, et al. Evaluation of a diabetes management program in China demonstrated association of improved continuity of care with clinical outcomes. J Clin Epidemiol. 2008;61(9):932-9.

68. Hanafi NS, Abdullah A, Lee PY, Liew SM, Chia YC, Khoo EM. Personal continuity of care in a university-based primary care practice: impact on blood pressure control. PLoS One. 2015;10(7):e0134030.

69. Zhang $Y$, Tang W, Zhang $Y$, Liu L, Zhang L. Effects of integrated chronic care models on hypertension outcomes and spending: a multi-town clustered randomized trial in China. BMC Public Health. 2017;17:244.

70. Ye T, Sun X, Tang W, Miao Y, Zhang Y, Zhang L. Effect of continuity of care on health-related quality of life in adult patients with hypertension: a cohort study in China. BMC Health Serv Res. 2016;16:674.

71. Shi L, Lee D-C, Liang H, Zhang L, Makinen M, Blanchet N, et al. Community health centers and primary care access and quality for chronically-ill patients - a case-comparison study of urban Guangdong Province, China. Int J Equity Health. 2015;14:90.

72. Wei X, Li H, Yang N, Wong SYS, Chong MCS, Shi L, et al. Changes in the perceived quality of primary care in Shanghai and Shenzhen, China: a difference-in-difference analysis. Bull World Health Organ. 2015;93(6):407-16.

73. Shi L, Makinen M, Lee D-C, Kidane R, Blanchet N, Liang H, et al. Integrated care delivery and health care seeking by chronically-ill patients - a casecontrol study of rural Henan province, China. Int J Equity Health. 2015:14:98.

74. Mwangome M, Geubbels E, Klatser P, Dieleman M. Perceptions on diabetes care provision among health providers in rural Tanzania: a qualitative study. Health Policy Plan. 2017;32(3):418-29.

75. Mwangome MN, Geubbels E, Klatser P, Dieleman M. "I don't have options but to persevere." Experiences and practices of care for HIV and diabetes in rural Tanzania: a qualitative study of patients and family caregivers. Int J Equity Health. 2016;15:56.

76. Wei X, Barnsley J, Zakus D, Cockerill R, Glazier R, Sun X. Assessing continuity of care in a community diabetes program: initial questionnaire development and validation. J Clin Epidemiol. 2008;61(9):925-31.

77. Vargas I, Garcia-Subirats I, Mogollón-Pérez AS, De Paepe P, da Silva MRF, Unger J-P, et al. Patient perceptions of continuity of health care and associated factors. Cross-sectional study in municipalities of central Colombia and north-eastern Brazil. Health Policy Plan. 2017;32(4):549-62.

78. Donaldson MS. Continuity of care: a reconceptualization. Med Care Res Rev. 2001;58(3):255-90.

79. Reid R, Haggerty J, McKendry R. Defusing the confusion: concepts and measures of continuity of healthcare. Ottawa: Canadian Health Services Research Foundation; 2002

80. Definition of Continuity in English. Oxford Dictionaries: British \& World English. https://en.oxforddictionaries.com/definition/continuity. Accessed 9 Feb 2018.

81. Definition of Continuum in English. Oxford Dictionaries: British \& World English. https://en.oxforddictionaries.com/definition/continuum. Accessed 9 Feb 2018.

82. Uijen AA, Heinst CW, Schellevis FG, van den Bosch WJHM, van de Laar FA, Terwee $\mathrm{CB}$, et al. Measurement properties of questionnaires measuring continuity of care: a systematic review. PLoS One. 2012;7(7):e42256.

83. Parker G, Corden A, Heaton J. Synthesis and Conceptual Analysis of the SDO's Programme's Research on Continuity of Care: Report for the National Institute for Health Research Service Delivery and Organisation Programme. Southampton: National Institute for Health Research Evaluations, Trials and Studies Coordinating Centre; 2010. http://www.netscc.ac.uk/hsdr/files/ project/SDO_FR_08-1813-248_V01.pdf. Accessed 11 Feb 2018.
84. World Health Organization. Universal Health Coverage (UHC): Fact Sheets. 2017. http://www.who.int/en/news-room/fact-sheets/detail/universal-healthcoverage-(uhc). Accessed 6 May 2018.

85. Bown MJ, Sutton AJ. Quality control in systematic reviews and metaanalyses. Eur J Vasc Endovasc Surg. 2010;40:669-77.

86. Salisbury C, Sampson F, Ridd M, Montgomery AA. How should continuity of care in primary health care be assessed? Br J Gen Pract. 2009;59(561):e134e141. https://doi.org/10.3399/bjgp09X420257

\section{Ready to submit your research? Choose BMC and benefit from:}

- fast, convenient online submission

- thorough peer review by experienced researchers in your field

- rapid publication on acceptance

- support for research data, including large and complex data types

- gold Open Access which fosters wider collaboration and increased citations

- maximum visibility for your research: over $100 \mathrm{M}$ website views per year

At BMC, research is always in progress.

Learn more biomedcentral.com/submissions 